\title{
Spatial Distribution of Coffee Wilt Disease Under Roguing and Replanting Conditions: A Case Study from Kaweri Estate in Uganda
}

\author{
F. Pinard, S. E. Makune, P. Campagne, and J. Mwangi
}

First author: CIRAD UR 106 Bioagresseurs/icipe, Plant Health Department, P.O. Box 30772, Nairobi 00100, Kenya; second and fourth authors: Kaweri Coffee Plantation Ltd., P.O. Box 264, Mubende, Uganda; and third author: Institute of Integrative Biology, University of Liverpool, Liverpool L69 7ZB, UK.

Accepted for publication 6 June 2016.

\begin{abstract}
Pinard, F., Makune, S. E., Campagne, P., and Mwangi, J. 2016. Spatial distribution of coffee wilt disease under roguing and replanting conditions: A case study from Kaweri estate in Uganda. Phytopathology 106:1291-1299.

Based on time and spatial dynamic considerations, this study evaluates the potential role of short- and long-distance dispersal in the spread of coffee wilt disease (CWD) in a large commercial Robusta coffee estate in Uganda (Kaweri, 1,755 ha) over a 4-year period (2008 to 2012). In monthly surveys, total disease incidence, expansion of infection foci, and the occurrence of isolated infected trees were recorded and submitted to spatial analysis. Incidence was higher and disease progression faster in old coffee plantings compared with young plantings, indicating a lack of

efficiency of roguing for reducing disease development in old plantings. At large spatial scale (approximately $1 \mathrm{~km}$ ), Moran indices (both global and local) revealed the existence of clusters characterized by contrasting disease incidences. This suggested that local environmental conditions were heterogeneous or there were spatial interactions among blocks. At finer spatial scale (approximately $200 \mathrm{~m}$ ), O-ring statistics revealed positive correlation between distant infection sites across distances as great as $60 \mathrm{~m}$. Although these observations indicate the role of short-distance dispersal in foci expansion, dispersal at greater distances $(>20 \mathrm{~m})$ appeared to also contribute to both initiation of new foci and disease progression at coarser spatial scales. Therefore, our results suggested the role of aerial dispersal in CWD progression.
\end{abstract}

Fusarium xylarioides Heim \& Saccas (teleomorph $=$ Gibberella xylarioides) is the causal agent of coffee wilt disease (CWD) (Booth 1971), responsible for a vascular and lethal infection of the plant. The disease is restricted to the African continent, where it has been known since coffee production began there (Musoli et al. 2008; Rutherford 2006). During the 1950s, CWD was responsible for a decline in the use of Coffea abeokutae, C. excelsa, and C. neoarnoldiana as commercial crops in central and western Africa (Meifren 1961; Saccas 1956). Currently, CWD is causing severe damage to crops of C. canephora (Pierre) var. Robusta in the Democratic Republic of Congo, Uganda, and northeastern Tanzania (Musoli et al. 2008; Tshilenge-Djim et al. 1998) and economically endangering the local production system (Rutherford 2006). F. xylarioides has also been reported infecting $C$. arabica in Ethiopia since the early 1960s and is now considered the major cause of crop losses there (Girma and Hindorf 2001; Kranz and Mogk 1973; Lejeune 1958); recent work suggests the existence of a specialized population of the pathogen developing only on C. arabica (Buddie et al. 2015). Furthermore, the disease is a potentially serious threat to coffee cultivation in other major Afrotropical C. arabica-growing regions in Kenya, Uganda, Tanzania, Rwanda, and Burundi, where it has not yet been detected.

As with many other wilt agents, $F$. xylarioides develops within the xylem, which becomes progressively obstructed. At an early stage, infection is limited to one stem and generates a typical black-purple discoloration of the external wood, visible only after bark removal (Saccas 1956). No external symptoms can be seen and the disease remains cryptic for a few weeks to a few months until the vessels become completely obstructed, which causes the stem to suddenly wilt and the foliage to be lost. The pathogen further colonizes the other stems of the plant via the central trunk, leading to its rapid

Corresponding author: F. Pinard; E-mail address: fabrice.pinard@cirad.fr death. It is only at this final stage that fruiting bodies (pycnidia) of the pathogen are produced, generally at the surface of the basal part of the coffee trunk (Saccas 1951).

Knowledge of the epidemiology of CWD remains fragmented and is mostly derived, even today, from work done during the $1950 \mathrm{~s}$ in Central Africa (Musoli et al. 2008). The destructive potential of F. xylarioides is a result of the rapidly expanding foci of infection that develop within a plot (Musoli et al. 2008; Saccas 1951), leading various authors to suggest that the pathogen was soilborne (Girma and Hindorf 2001; Jacques-Felix 1954; Rutherford 2006). Shortdistance dispersal of the pathogen has attracted the most biological and epidemiological research attention, leading to the general assumption that $F$. xylarioides could infect neighboring trees after penetration of either the superficial roots of adjacent plants or, most probably, the basal parts of the stem (Saccas 1951). However, the dispersal mechanisms involved in this process have not been demonstrated categorically yet. Compared with short-distance dispersal, medium- and long-distance dispersal of the pathogen have received far less research attention. How the disease progresses from one coffee plot to another and how the disease front progresses in a previously disease-free environment remains unknown; this is despite the observations of Delassus (1954), who estimated that the speed of the disease progression was $50 \mathrm{~km}$ in 2 years. Some authors (Booth 1971; Renaud 1958; Saccas 1956) have suggested that long-distance dispersal might result from the aerial dissemination of the pathogen but this hypothesis remains to be tested.

The many remaining uncertainties surrounding CWD epidemiology, particularly regarding the infection process and dissemination mechanisms, have hampered the development of modern, efficient, and economically viable control methods that would benefit African smallholder coffee farmers. In the present study, we address the question of the spatial dynamics of CWD at a spatial scale of approximately $10 \mathrm{~km}$, in the relatively homogeneous environment of a commercial estate of $C$. canephora. Our objective was to detect and describe the characteristic spatial patterns of CWD and relate these to 
the potential mechanisms for F. xylarioides spread; in particular, we made regular and exhaustive surveys of infection foci, which are related to short-distance dispersal, and infection in isolated trees, which could be related to long-distance dispersal. Our study was made at two spatial scales. At the smaller scale (i.e., the scale of blocks of coffee trees), the position of infected trees was identified and the spatial distribution of the disease within the block was treated as a point pattern. O-ring statistics were used to evaluate the spatial correlation between infected trees. At the larger scale (i.e., the entire estate, consisting of 148 blocks), infected trees within each block were numbered and categorized according to their degree of isolation. In this case, the spatial distribution of CWD was assessed using Moran statistics to detect areas larger than a block that had particularly low or particularly high incidences of CWD, which would indicate potential interactions between blocks (for example, a heavily infected block may contaminate its neighbors if we assume that long-distance dissemination does occur).

The surveyed estate used a control program based on the rapid removal of CWD-infected trees as soon as they are detected (i.e., roguing) followed by delayed replanting after approximately 2 years. This control program clearly has an impact on the development of disease epidemics but also provides a fast and easy way to identify foci of infection (i.e., the empty spaces where infected trees have been removed). Furthermore, we based our work on the assumption that the control program would mainly affect quantitative aspects of the epidemic such as the incidence level but would not be efficient enough to prevent the occurrence of CWD dissemination events. This meant that our proposed pattern analysis was feasible; it was beyond the scope of this work to document and analyze the quantitative impact of roguing and replanting as a control strategy for CWD, although we do consider the implications of these measures on our results in the Discussion section.

\section{MATERIALS AND METHODS}

The Kaweri estate context. Kaweri coffee estate is close to Mubende in Uganda $\left(0^{\circ} 37^{\prime} 40^{\prime \prime} \mathrm{N}, 31^{\circ} 28^{\prime} \mathrm{E}\right)$. The estate covers an area of 2,800 ha, including 1,755 ha of Robusta coffee (C. canephora), grown as a single crop under natural or planted shade trees. The remaining land consisted of a valley bottom covered with natural forest. Initial planting occurred between 2001 and 2004, leading to the production of 151 blocks of variable size, ranging from 1.7 to 35.2 ha.

TABLE 1. Blocks investigated for low scale coffee wilt disease (CWD) spatial pattern analysis ${ }^{\mathrm{a}}$

\begin{tabular}{|c|c|c|c|c|c|c|}
\hline \multirow[b]{2}{*}{ Block } & \multirow[b]{2}{*}{ Planting year } & \multirow[b]{2}{*}{ Area (ha) } & \multirow[b]{2}{*}{ Focus size } & \multicolumn{3}{|c|}{ Number of foci } \\
\hline & & & & 2008 & 2011 & 2012 \\
\hline \multirow[t]{3}{*}{ Kyam 1B } & 2001 & 8.5 & $\mathrm{~F}$ & 52 & - & - \\
\hline & & & $\mathrm{P}$ & 42 & - & - \\
\hline & & & $S$ & 78 & - & - \\
\hline \multirow[t]{3}{*}{ Kyam 3A } & 2002 & 9.4 & F & 19 & - & - \\
\hline & & & P & 42 & - & - \\
\hline & & & $S$ & 72 & - & - \\
\hline \multirow[t]{3}{*}{ Kyam 6B } & 2003 & 4.9 & $\mathrm{~F}$ & 0 & 0 & - \\
\hline & & & $P$ & 12 & 6 & - \\
\hline & & & $S$ & 31 & 28 & - \\
\hline \multirow{3}{*}{ Kyam 8C } & 2003 & 8.5 & $\mathrm{~F}$ & 0 & 0 & - \\
\hline & & & $\mathrm{P}$ & 18 & 3 & - \\
\hline & & & $S$ & 48 & 38 & - \\
\hline \multirow[t]{3}{*}{ Kite $5 \mathrm{~B}$} & 2003 & 4.5 & $\mathrm{~F}$ & - & 0 & 0 \\
\hline & & & P & - & 0 & 0 \\
\hline & & & $S$ & - & 14 & 4 \\
\hline \multirow[t]{3}{*}{ Kite $5 \mathrm{C}$} & 2003 & 35.2 & F & - & 1 & 0 \\
\hline & & & $\mathrm{P}$ & - & 12 & 0 \\
\hline & & & $S$ & - & 19 & 26 \\
\hline
\end{tabular}

${ }^{a} \mathrm{~S}=$ single-tree focus, $\mathrm{P}=$ two- to five-tree focus, and $\mathrm{F}=$ more than five-tree focus; $-=$ no observation made.
Only 148 blocks were considered in this study because only incomplete data were available for three blocks. Coffee trees were planted according to the recommended cropping practices for Robusta in Uganda (i.e., a mixture of six coffee clones planted at a density of 3.3 by $3.3 \mathrm{~m}$, equivalent to 1,111 trees $\mathrm{ha}^{-1}$ ). Planted clones included the CWD-susceptible 1s/2, 1s/3, 223/32, and 257/53 (Musoli et al. 2008) and the clones $1 \mathrm{~s} / 6$ and $258 / 24$, for which susceptibility to CWD is suspected (F. Pinard, personal observations).

CWD control measures (i.e., roguing and replanting, as described previously) were initiated at Kaweri in 2006 when infected trees were still uncommon. They were further extended in 2008 when the presence of disease became more widespread. All blocks were inspected monthly by a team of specially trained technical staff to ensure early detection of new CWD cases. Typical CWD symptoms that cannot be confused with other disease include partial wilting of coffee foliage and the absence of root rotting. Once an infected tree was detected, it was immediately removed and burnt on site to reduce the risk of disease spread. As a consequence, empty spaces were left within the coffee rows, which remained until replanting of young coffee trees after a period of approximately 2 years.

CWD spatial distribution at the commercial block level: Disease assessment. Disease incidence was detected after roguing from the empty spaces left after tree removal. During the survey, the estate was practically free of any other diseases and, therefore, it was possible to assume that CWD was the only possible cause of tree gap in a block during the study. Six commercial blocks were evaluated in 2008 to analyze the spatial distribution of disease. Spatial positions of infection foci were georeferenced using a GPS device and each block was surveyed on a single day to ensure accuracy of the spatial coordinates (approximately 5 to $7 \mathrm{~m}$ ). Any contiguous empty spaces were considered to be a focus and were assigned a class according to their size: $\mathrm{S}=$ a single-tree infection site (i.e., an individual tree gap that was not contiguous with any other gap), $\mathrm{P}=$ two to five infected trees, and $\mathrm{F}=$ more than five trees infected. To facilitate the process of focus identification, trunks of healthy trees nearby were marked. From the six blocks, four blocks were selected that had two contrasting patterns of CWD infection (Table 1). Kyam 1B and 3A were old plantings (2001 and 2002) with high incidences of CWD and large foci sizes. In contrast, blocks Kyam 8C and 6B were young plantings (2003) with low incidences of CWD and smaller foci sizes. These blocks were evaluated again in 2011. Kyam 1B and 3A were then excluded from subsequent evaluations because many of the larger foci had merged and could no longer be distinguished from each other. To compensate for this loss, two additional young planting blocks, Kite 5B and 5C, were evaluated in 2011 and 2012.

CWD spatial distribution at the commercial block level: Statistical methods. The analysis of the foci distribution map was based on the O-ring statistic O(r) proposed by Wiegand et al. (1999) (additional details provided in Appendix 1), which offers multitype point pattern analysis and an immediate reading of the spatial correlation between infected trees. $\mathrm{O}(\mathrm{r})$ was calculated to detect the possible influence of the location of older foci on the spatial distribution of younger foci. CWD distribution maps were prepared including all foci categories (size and detection date) and the block's contour. O-ring statistics were estimated from these maps after correction for edge effects using the method of Ohser (1983), which was well adapted to irregularly shaped domains. Calculations were made using the statspat package in the $\mathrm{R}$ programming environment (Baddeley and Turner 2005) and assumed homogeneity of the point pattern. The Diggle-Cressie-Loosmore-and-Ford test (Baddeley and Turner 2005) with 999 iterations was used to assess the significance of the total deviation of the O-ring statistics from a pure random spatial distribution of foci, and was estimated from a Poisson random process. When the test indicated a significant difference $(P<0.05)$ between the two distributions, the deviation of the O-ring statistics from random expectation was 
investigated further at any distance by computing simulation envelopes (999 iterations). Specific analyses are described below.

All foci distribution analysis. This analysis aimed at characterizing the spatial pattern of the distribution of all foci, regardless of the date they were observed or their size. For each block, all observations were combined and the foci distribution map was analyzed as a univariate point pattern. As a summary of the analysis, interfoci distances were calculated for each block, regardless of the foci category. Distances were further grouped to generate a histogram and a density function of their global distribution.

Influence of older infection foci on later occurrences of CWD. We investigated how the location of old foci may have influenced the occurrence of new infections. For each block, the foci mapped were treated as bivariate point patterns with two categories: recent foci and older foci. The categories were defined based on the date the foci were detected. Foci detected in 2008 in Kyam 6B and Kyam $8 \mathrm{~B}$ were older foci than those detected in 2011; foci detected in 2011 in Kite 5B and Kite 5C were older foci than those detected in 2012.

Influence of large disease foci on the occurrence of small disease foci. We investigated how the location of large foci influenced the occurrence of single-tree infections. For each block, foci maps were considered to be bivariate point patterns with two categories of foci: large and small ones. Both $\mathrm{P}$ and $\mathrm{F}$ foci categories were considered to be large while the $\mathrm{S}$ category was considered to be small. We used data from observations made in 2008 in blocks Kyam 1B and Kyam 3A, cumulative data from 2008 and 2011 observations in blocks Kyam 6B and Kyam 8C, and cumulative data from 2011 and 2012 observations in the block Kite 5C. Data from block Kite 5B were not used in the analysis because CWD incidence in this block was associated with S-class foci only.

CWD spatial distribution at estate level: Disease assessment. Disease incidence was assessed from the number of trees expressing CWD symptoms (wilted foliage or drying stem), as detected in the monthly inspections. From March 2008 to October 2012, the number of new disease occurrences was recorded monthly on each of the estate's blocks. Newly infected trees were characterized according to the distance separating them from the closest site of previously detected infection (i.e., an empty planting location in a row). New infections were recorded as $\mathrm{N}_{1} \mathrm{~N}_{2}, \mathrm{~N}_{3}$, or $\mathrm{N}_{4}$ depending on whether they were separated from an earlier infection by 12,3 , or 4 interplant spaces, respectively. For practical reasons, rapid location of old infection sites that were more distant than four interplant spaces from new infections (equivalent to 12 to $15 \mathrm{~m}$ ) was difficult; these new infections, therefore, were considered to be isolated and scored as N. For easy and fast tree characterization during successive survey rounds, the trunks of the healthy trees bordering the foci location were marked. Because all coffee blocks in Kaweri are under a roguing control program, no control blocks were available during the survey to assess the development of CWD in the absence of control measures.

The estate's archives were used to estimate CWD incidence over the period of 2006 to 2008 , when the epidemic first began to develop on the estate. These data were used to evaluate total disease incidence from 2006 to 2008 but were not sufficiently precise for inclusion in the spatial distribution analysis.

CWD spatial distribution at estate level: Statistical methods. At the estate level, the data used were the monthly number of new CWD occurrences per block between March 2008 and October 2012 (estate archive data not included). Records were cumulative over time for each tree category $\left(\mathrm{N}, \mathrm{N}_{1} \mathrm{~N}_{2}, \mathrm{~N}_{3}\right.$, and $\mathrm{N}_{4}$ ) and for each of the four planting years (2001 to 2004) in order to estimate the progression of disease. When required, cumulative incidences were compared using a $\chi^{2}$ test.

For the total cumulative incidence of CWD per block at the end of the final survey in October 2012, the effect of planting date (i.e., age) on disease incidence was analyzed using a GLM procedure and a binomial variance distribution after logit transformation (Madden and Hughes 1995).
The spatial distribution analysis of disease incidence on the estate was made on the total cumulative number of occurrences of CWD per block, as recorded in October 2012, after removal of the effect of age on incidence. This was achieved by analysis of the blocks' residuals recorded from the abovementioned GLM procedure.

Analysis was based on calculation of the Moran I global index (Cliff and Ord 1981; Moran 1948) at the scale of the estate, and its locally derived indicators (local indicators of spatial association [LISA]) (Anselin 1995) (additional details provided in Appendix 2). Moran indices are considered to be robust statistics (Chessel and Thioulouse 2003) effective at detecting and characterizing spatial heterogeneity in distribution patterns. They were calculated in this study with the aim of detecting possible interactions between blocks (i.e., the possibility that the level of disease incidence in a given block somehow influenced the level of disease incidence in neighboring blocks). In this study, the neighborhood of a block included all surrounding blocks that were closer than $0.54 \mathrm{~km}$, this distance being the maximum distance between two contiguous blocks on the estate. When a significant level of association was detected at the scale of the entire estate, LISA were estimated to detect, at the small scale, which of the neighborhood associations differed significantly from the estate average.

Moran indices were calculated separately for the isolated $(\mathrm{N})$ tree category and the clustered $\left(\mathrm{N}_{1}+\mathrm{N}_{2}+\mathrm{N}_{3}+\mathrm{N}_{4}\right)$ tree category. Moran scatter plots showing the neighborhood value of each block against the block's value were drawn in both cases. LISA were further calculated to determine which of the 148 couples (neighborhood/ block) were significantly more similar than would be expected from a random distribution of the blocks' values. Significant associations were finally included on the estate's map to visualize the results.

Computations for this analysis were done using the sp and spdep packages in the $\mathrm{R}$ programming environment (Bivand et al. 2013a,b).

\section{RESULTS}

Small-scale spatial organization of CWD foci, from 10 to a few hundred meters (block level). In 2008, at the beginning of the study, blocks Kyam 1B and Kyam 3A had 172 and 133 foci, respectively, many of which were large (type $\mathrm{P}$ and $\mathrm{F}$ ) (Table 1). Blocks Kyam 6B and 8C had a lower incidence of CWD and large foci were absent (Table 1). In 2011, the incidence of CWD had increased similarly in both Kyam 6B and 8C; mainly single infected trees and a few small-sized $\mathrm{P}$ foci were observed. No large-sized $\mathrm{F}$ foci had developed during the period in Kyam 6B and 8C (Table 1). During the period 2011 to 2012, the disease increased in the same way in blocks Kite 5B and 5C as it had done in Kyam 6B and 8C; mainly single infected trees and a few small-sized $\mathrm{P}$ foci had developed.

All foci distribution. When all foci were considered as one category, their spatial distributions were different from a random distribution on all six blocks ( $P$ values varied from 0.001 to 0.032 , depending on the block). Aggregation was detected for distances less than $10 \mathrm{~m}$ (Figs. 1A and 2A for the block Kyam 1B as an example; other blocks not shown). With increasing distance, aggregation was less pronounced; at a distance of 40 to $50 \mathrm{~m}$, it was still detected in blocks Kyam 3A, 6B, and 1B and Kite 5B but not in blocks Kyam $8 \mathrm{C}$ and Kite 5C. When all interfoci distances were combined, $75 \%$ of the measured distances were shorter than $13 \mathrm{~m}$, the mean distance was $10.9 \mathrm{~m}$, and the median was $6.9 \mathrm{~m}$ (Fig. 2D). The distribution tail extended beyond $60 \mathrm{~m}$, with extreme values as far as 118 and $129 \mathrm{~m}$.

Influence of the location of old foci on the distribution of young foci. When foci categories were derived from the date of observation, the O-ring statistic revealed an aggregation trend for younger foci surrounding older foci at the $10-\mathrm{m}$ scale (Fig. 2B for block Kyam 6B as an example; other blocks not shown). This trend was highly significant $(P<0.002)$ for Kyam 6B and $8 \mathrm{C}$ and Kite 5C, 
and weaker for Kite 5B $(P=0.058)$. Beyond $10 \mathrm{~m}$, the aggregation pattern was not always detected. It was still observed as far as $50 \mathrm{~m}$ in Kite $5 \mathrm{C}$ but reduced and limited to $20 \mathrm{~m}$ in Kyam 6B (Fig. 2B). It was not seen on Kyam $8 \mathrm{C}$ or Kite $5 \mathrm{~B}$.

Influence of the distribution of large foci on the occurrence of small disease foci. When foci categories were derived from the focus size, the influence of the location of large foci on the distribution of small foci was significant ( $P$ values varied from 0.001 to 0.014 , depending on the block), revealing an accumulation of small foci around large ones at a distance of approximately $10 \mathrm{~m}$ (Figs. 1B and 2C for block Kyam 6B as an example; other blocks not shown). A weaker aggregated pattern was still detected at a distance of 40 to $50 \mathrm{~m}$ in Kyam $3 \mathrm{~A}$ and $6 \mathrm{~B}$ but not in Kyam $8 \mathrm{C}$ and $1 \mathrm{~B}$ and Kite 5C. In Kyam 6B (Fig. 2B), a higher level of aggregation was detected because infected trees appeared organized in clusters at a distance of $20 \mathrm{~m}$ from each other, as revealed by the shape of the O-ring curve, with successive maxima at 20, 35 to 40 , and $60 \mathrm{~m}$.

Large-scale spatial organization of CWD foci, from $500 \mathrm{~m}$ to $10 \mathrm{~km}$ (estate level). After the noticeable outbreak of CWD in 2006, the mean increase in disease incidence during the subsequent 2 years was estimated as $0.7 \%$ (0.01 to 3.9\%, depending on the block) from the estate archives (Table 2). Older plantings (2001 and 2002) had a three to five times higher incidence of disease than the younger ones (2003 and 2004). From 2008 to 2012, the
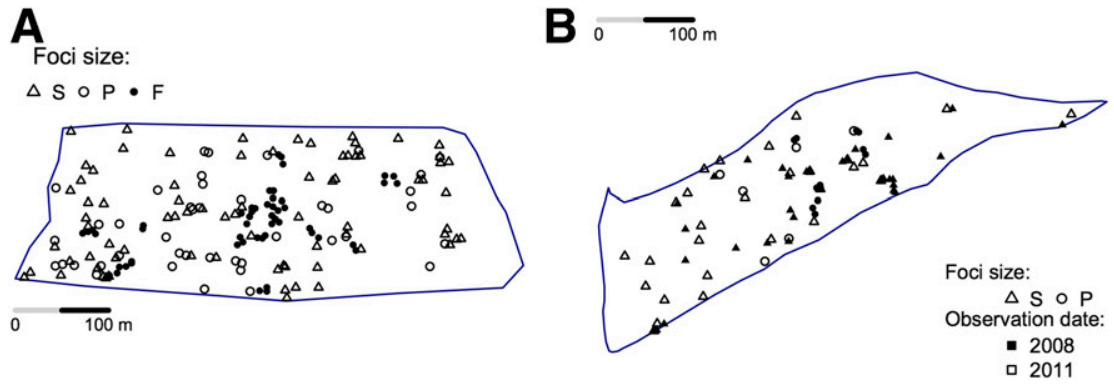

Fig. 1. Map of blocks and foci size. A, Block Kyam $1 \mathrm{~B}$ and $\mathbf{B}$, block Kyam $6 \mathrm{~B} . \mathrm{S}=$ Single-tree foci, $\mathrm{P}=2$ - to 5 -tree foci, and $\mathrm{F}=$ foci with more than 5 trees.
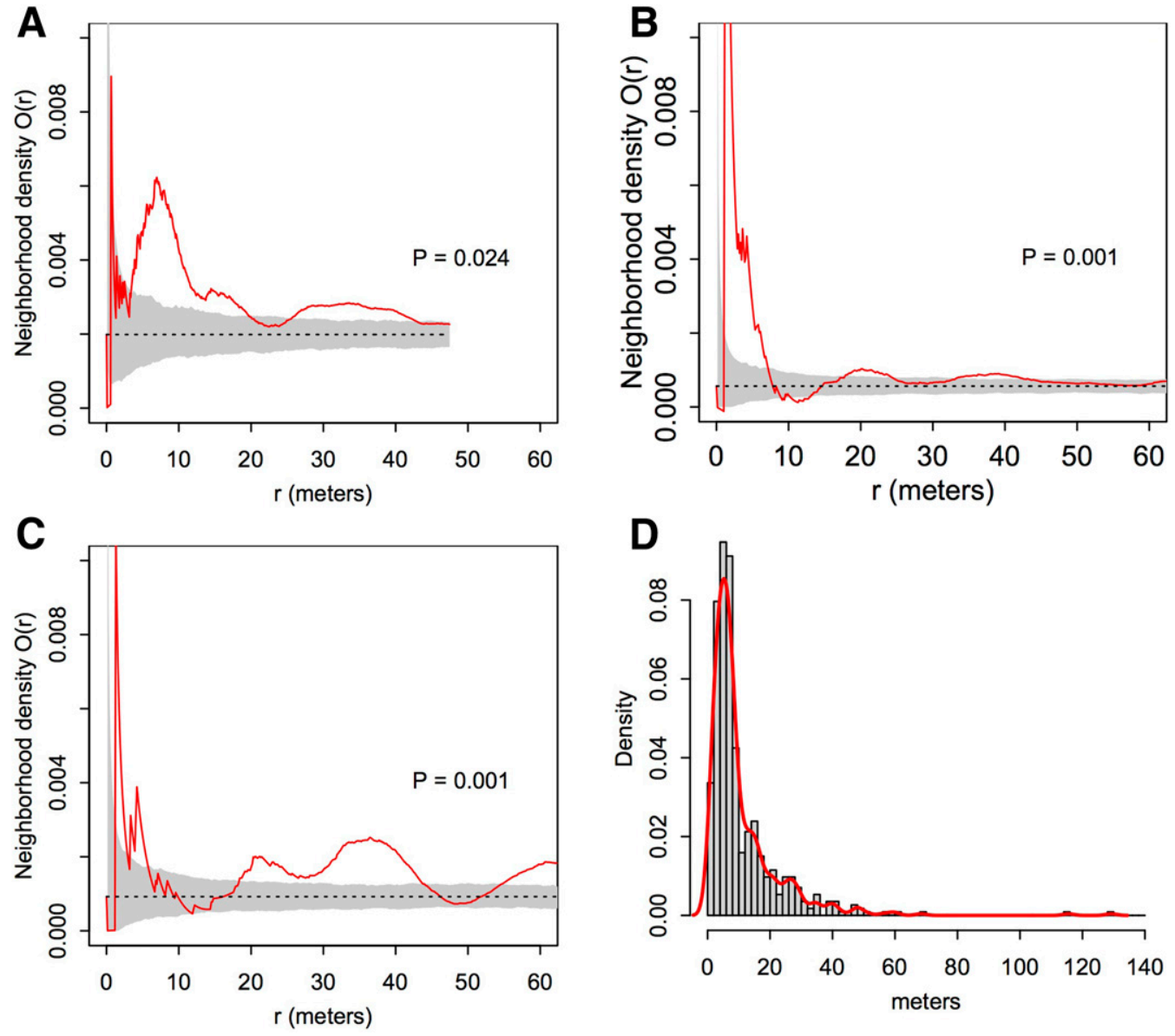

Fig. 2. O-ring $(\mathrm{O}(\mathrm{r}))$ statistics of coffee wilt disease foci distribution pattern. A, Block Kyam 1B; $\mathrm{O}(\mathrm{r})=$ the expected density of foci according to the interfoci distance. B, Block Kyam 6B; O(r) = the expected density of single-tree $(\mathrm{S})$ foci at distance $\mathrm{r}$ away from a multitree $(\mathrm{P}$ or F) focus. C, Block Kyam 6B; O(r) $=$ the expected density of foci detected in 2011 at distance $r$ away from a focus detected in the block in 2008. D, Interfoci distance distribution (histogram and estimated density [dark line]), based on cumulative observations from the six blocks Kite 5B and 5C and Kyam 1B, 3A, 8C, and 6B. All foci categories were considered in the calculation. The solid line indicates O(r) statistics, the gray area simulates the variability in the null hypothesis based on 999 iterations of a spatially random Poisson process, and the dotted line indicates intensity of the observed spatial pattern (number of observations per unit area). $\mathrm{P}=$ probability for $\mathrm{O}(\mathrm{r})$ to be the realization of a spatially random Poisson process. 
mean disease incidence increased by $1.6 \%$ (0.02 to $13.5 \%$, depending on block) across the estate. In summary, cumulative losses between 2006 and 2012 were estimated at $2.3 \%$ ( 0.1 to $17.3 \%$, depending on block), which was equivalent to 63,000 dead trees. This represented an average loss of 10,500 trees per year, equivalent to approximately 9.5 ha of the entire coffee crop.

The block distribution map per planting date (Fig. 3) and the cumulative disease incidence map (as per October 2012) (Fig. 4) suggested a relationship between the incidence of CWD and the age of the block (Table 2). Disease developed faster during 2008 to 2012 in older blocks: $5.4 \%$ in the 2001 plantings versus $3.5,0.7$, and $0.3 \%$ in the 2002, 2003, and 2004 plantings, respectively (Table 2). Regression analysis (GLM) on the cumulative incidence data (as per October 2012) confirmed the significance of this observation $\left(P<10^{-10}\right)$. The effect of age was further analyzed considering tree category and degree of isolation ( $\mathrm{N}=$ isolated-tree category; $\mathrm{N}_{1}, \mathrm{~N}_{2}$, $\mathrm{N}_{3}$, and $\mathrm{N}_{4}$, = clustered-tree categories) (Fig. 5A to D). In 2001 and 2002 plantings, $\mathrm{N}_{1}$ trees were predominant among the newly infected trees detected, amounting to 5.22 and $3.23 \%$ of all inspected trees, respectively, in October 2012; the other infectedtree categories $\left(\mathrm{N}, \mathrm{N}_{2}, \mathrm{~N}_{3}\right.$, and $\left.\mathrm{N}_{4}\right)$ did not exceed $1 \%$ of the estate's tree population at the final survey (Fig. 5A and B). In 2003 plantings, the frequencies of $\mathrm{N}$ and $\mathrm{N}_{1}$ tree categories were similar and small $(0.6 \%)$; other tree categories were only detected at very low frequencies (less than 0.1\%) (Fig. 5C). In 2004 plantings, the $\mathrm{N}$ tree category was predominant but remained small until the final survey $(0.6 \%)$; the $\mathrm{N}_{1}$ tree category was approximately three times smaller than the $\mathrm{N}$ tree category $(0.2 \%)$ while frequencies of $\mathrm{N}_{2}, \mathrm{~N}_{3}$, and $\mathrm{N}_{4}$ tree categories were all less than $0.05 \%$ (Fig. 5D). Overall, the $\mathrm{N}, \mathrm{N}_{2}, \mathrm{~N}_{3}$, and $\mathrm{N}_{4}$ tree categories were always poorly represented, accounting for less than $0.7 \%$ of infected trees, regardless of the age of the block. The frequency of the $\mathrm{N}_{1}$ tree category was higher in old plantings than young plantings.

Overall, $\mathrm{N}, \mathrm{N}_{1}, \mathrm{~N}_{2}, \mathrm{~N}_{3}$, and $\mathrm{N}_{4}$ tree categories were positively correlated. The isolated-tree frequency $(\mathrm{N})$ varied with the frequencies of $\mathrm{N}_{1}, \mathrm{~N}_{2}, \mathrm{~N}_{3}$, and $\mathrm{N}_{4}$ but the correlations were relatively small, from 0.3 to 0.4 , suggesting a relative independence of the isolated $(\mathrm{N})$ and clustered $\left(\mathrm{N}_{1}, \mathrm{~N}_{2}, \mathrm{~N}_{3}\right.$, and $\mathrm{N}_{4}$, tree categories. Moreover, when all observations were compared, regardless of the planting date, the total number of $N$ trees detected $(6,536)$ was significantly greater $\left(\chi^{2}=5316, \mathrm{df}=1, P\right.$ approximately 0$)$ than the number of $\mathrm{N}_{4}$ infected trees at the margins of foci (398).

The I index for the $\mathrm{N}$ tree category was 0.1686 . This was relatively low and positive but also highly significant $(P=$ 0.001447 ), revealing a positive association among blocks with equivalent disease incidences. The LISA calculation detected 19 significant block-environment associations out of 148 (Fig. 6). Twelve of these were of the high/high type, corresponding to four clusters of blocks with high disease incidence (Fig. 7, clusters A to D), while seven of them were of the low/low type, corresponding to three clusters of blocks where the disease incidence was lower than the estate average (Fig. 7, clusters E, F, and G). These clusters appeared randomly scattered over the estate area, with no apparent structure underlying their distribution. Between these sites, the $\mathrm{N}$-tree category distribution was not related to any factor other than planting date.
The I index for the clustered-tree category $\left(\mathrm{N}_{1}, \mathrm{~N}_{2}, \mathrm{~N}_{3}\right.$, and $\mathrm{N}_{4}$ observations combined) was 0.34 . This was greater than the I index for the N population, positive, and also highly significant $\left(P<10^{-8}\right)$, revealing again a positive block-environment association at the estate level. The LISA calculation detected 14 significant associations (Fig. 8). Seven of these were of the high/high type and a further seven were of the low/low type. These associations constituted a unique cluster of blocks with very high CWD incidence on the southeastern margin of the estate (Fig. 9, cluster $\mathrm{H}$ ) and five clusters of very low CWD incidence (Fig. 9, clusters I to M) that were randomly scattered across the estate area. Interestingly, the distribution of the combined $\mathrm{N}_{1}+\mathrm{N}_{2}+\mathrm{N}_{3}+\mathrm{N}_{4}$ clusters appeared independent from that of the $\mathrm{N}$ category.

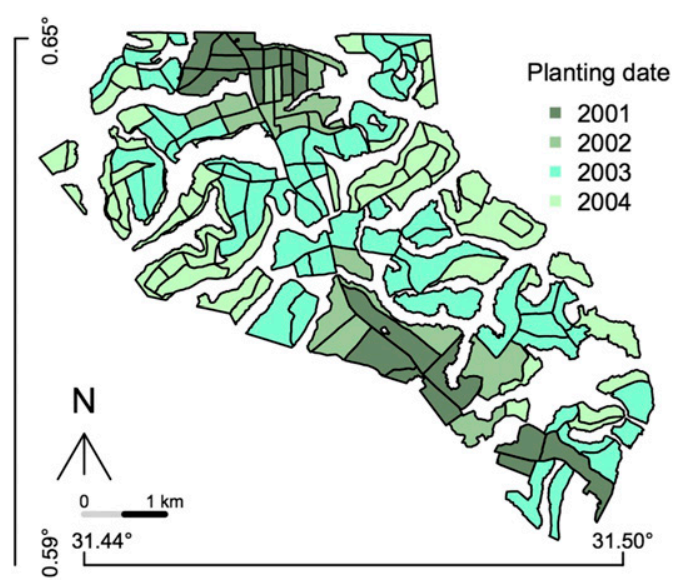

Fig. 3. Map of blocks at Kaweri coffee estate and their planting dates.

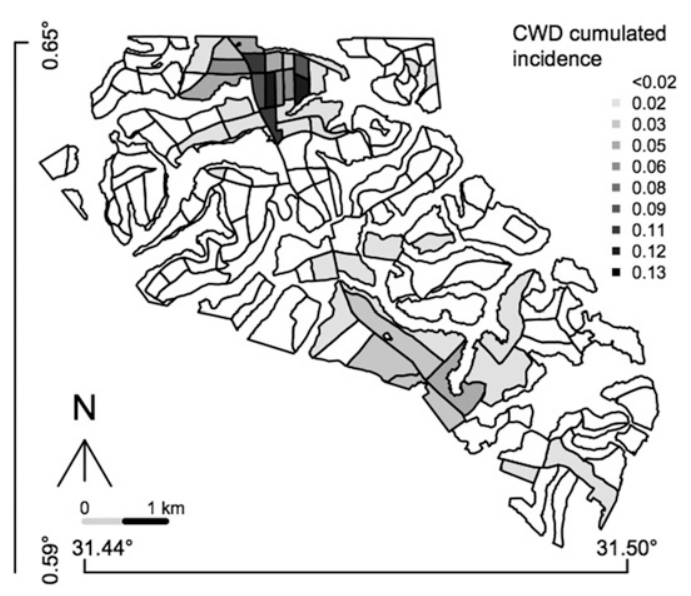

Fig. 4. Cumulative coffee wilt disease incidence per block at Kaweri Estate over the period from March 2008 to October 2012.

TABLE 2. Summary of coffee wilt disease (CWD) incidence (average proportion of infected trees per coffee block) at Kaweri Estate from 2006 to 2008 , 2008 to 2012, and 2006 to 2012 (cumulative) in blocks of trees planted at different times $(2001,2002,2003$, or 2004)

\begin{tabular}{lllllc}
\hline & \multicolumn{5}{c}{ CWD incidence per planting year } \\
\cline { 2 - 5 } Observation period & 2001 & 2002 & 2003 & 2004 & 0.003 \\
\hline 2006-2008 (from estate archives) & 0.015 & 0.013 & 0.005 & $0.007(0.0001,0.039)$ \\
2008-2012 (survey observations) & 0.054 & 0.035 & 0.007 & 0.003 & $0.016(0.0002,0.135)$ \\
2006-2012 (cumulative) & 0.069 & 0.048 & 0.013 & 0.006 & $0.023(0.001,0.173)$ \\
\hline
\end{tabular}

a Values in parenthesis are the extreme block incidences observed during the time period under consideration. 


\section{DISCUSSION}

This work illustrated two distinct processes for the spread of CWD: focus expansion, which is already known and well documented (Musoli et al. 2008; Saccas 1951), and focus initiation, which has never before been documented for CWD to our knowledge. Biological mechanisms leading to focus initiation are important to understand because they explain the progress of the CWD epidemic front at the scale of 100 to $200 \mathrm{~m}$, a scale larger than

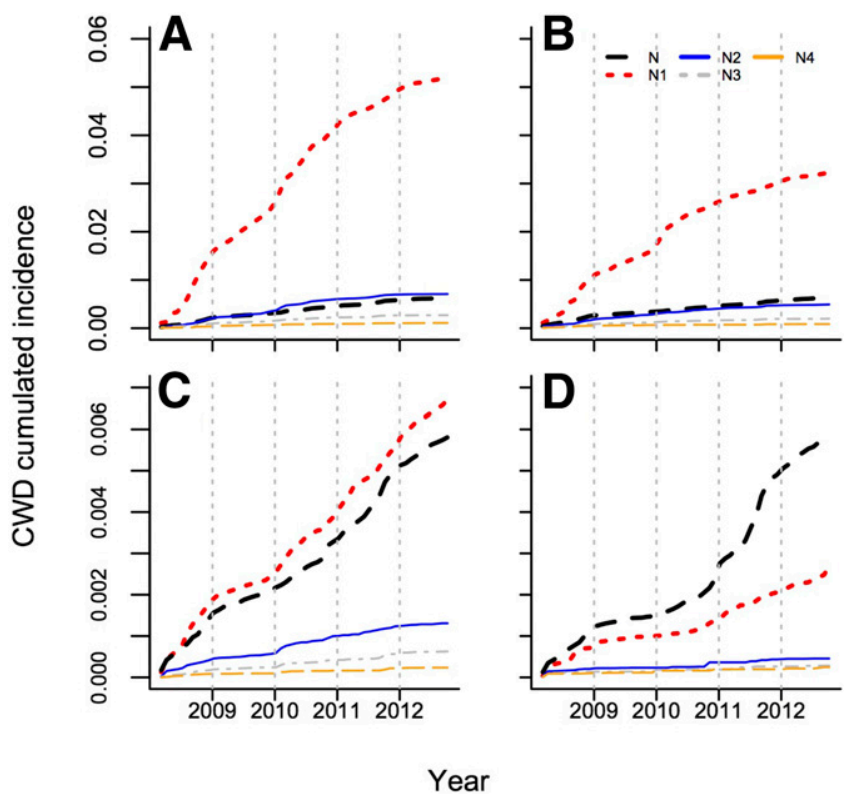

Fig. 5. Cumulative coffee wilt disease (CWD) incidence during the period from March 2008 to October 2012 at Kaweri coffee estate in relation to the year the trees were planted (A, 2001; B, 2002; C, 2003; and D, 2004) and the category of infection focus. $\mathrm{N}=$ isolated infected tree and $\mathrm{N} 1, \mathrm{~N} 2, \mathrm{~N} 3$, or $\mathrm{N} 4=$ clusters of infected trees where the nearest infected neighbor is $1,2,3$, or 4 interplant spaces distant, respectively.

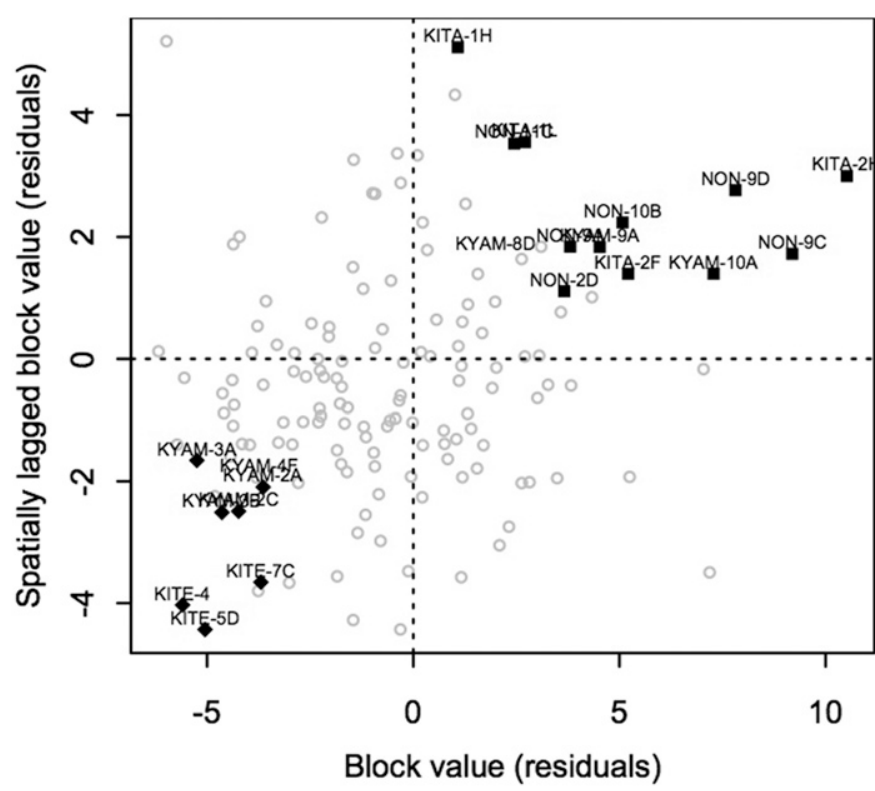

Fig. 6. Moran distribution plot of coffee wilt disease incidence in 148 commercial blocks of coffee at Kaweri estate between March 2008 and October 2012. Data based on the cumulative incidence of isolated infected trees $(\mathrm{N})$ corrected for the planting date and analyzed using GLM. X axis = block GLM residual value; $\mathrm{Y}$ axis $=$ average value of GLM residual values of neighboring blocks. Symbols: - = significant +/+ block-environment association (i.e., a block cluster with high levels of disease incidence) and $\downarrow=$ significant $-/-$ blockenvironment association (i.e., a block cluster with low levels of disease incidence). what would be observed if disease progress were only the result of focus expansion from tree to tree. The study provided a new perspective on the important phase of the $F$. xylarioides biological cycle, when the pathogen is disseminated and initiates new points of development; the results support a more complete understanding of the epidemiology of this fungus.

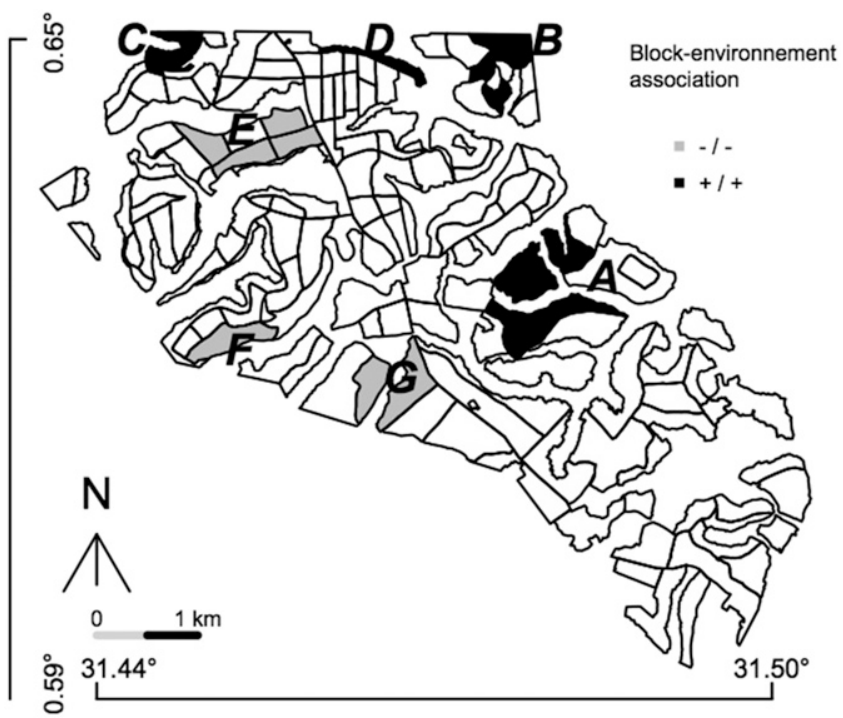

Fig. 7. Map showing the locations of blocks with significant blockenvironment associations at Kaweri estate with respect to isolated infected trees $(\mathrm{N})$. Dark areas $(+/+)$ indicate significant block-environment association with high levels of disease incidence: $\mathrm{A}=$ blocks Kite $1 \mathrm{~L}, 1 \mathrm{H}, 2 \mathrm{H}$, and $2 \mathrm{~F} ; \mathrm{B}=$ blocks Non 9D, 11C, 9C, 10B, and 8A; C = blocks Kyam 10A and 9A; and $\mathrm{D}=$ block Non 2D. Gray areas (-I-) indicate significant block-environment association with low levels of disease incidence: $\mathrm{E}=$ blocks Kyam 2C, 3B, 3A, and $2 \mathrm{~A} ; \mathrm{F}=$ block Kite $7 \mathrm{C}$; and $\mathrm{G}=$ blocks Kite $5 \mathrm{D}$ and 4 .

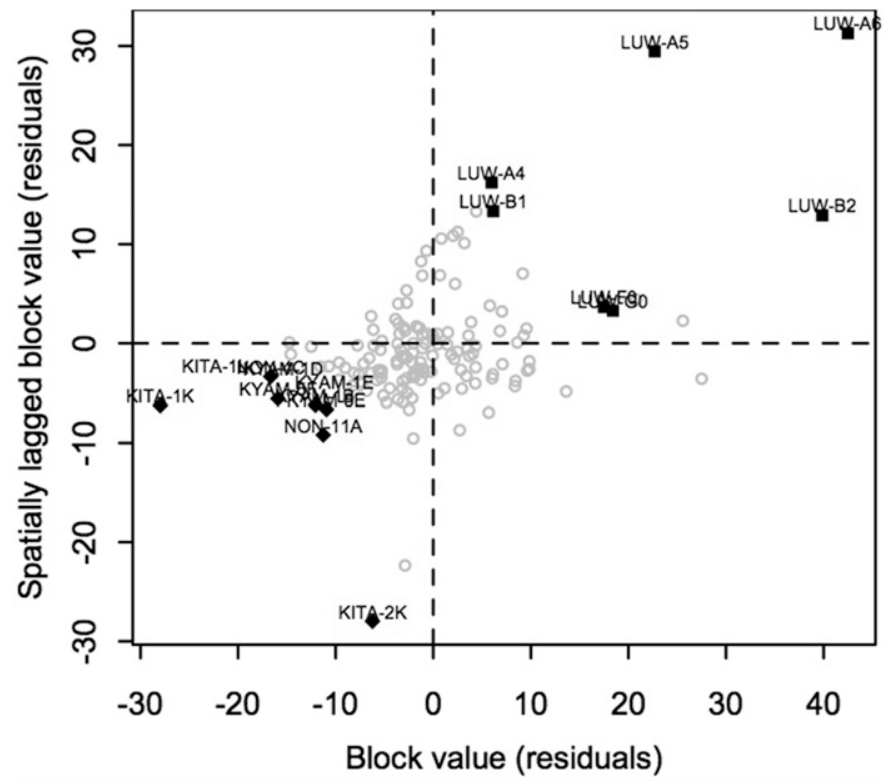

Fig. 8. Moran distribution plot of coffee wilt disease incidence in 148 commercial blocks of coffee at Kaweri estate between March 2008 and October 2012. Data based on the cumulative incidence of clustered infected tree categories (N1, N2, $\mathrm{N} 3$, and N4 types, as described previously), corrected for the planting date and analyzed by GLM analysis. $\mathrm{X}$ axis = block GLM residual values; $\mathrm{Y}$ axis = average value of GLM residual values of neighboring blocks. Symbols: - = significant +/+ block-environment association (i.e., a block cluster with high levels of disease incidence) and - significant $-/$ - block-environment association (i.e., a block cluster with low levels of disease incidence). 
The focus expansion process generated a neighbor-to-neighbor pattern of disease progression, which was fully captured by the frequencies of $\mathrm{N}_{1}, \mathrm{~N}_{2}, \mathrm{~N}_{3}$, and $\mathrm{N}_{4}$ tree categories (Fig. 5A to D). These provided a general description of the CWD focal front under the constraint of the control program: The frequency of the $N_{1}$ tree category was always clearly higher than the frequency of $\mathrm{N}_{2}, \mathrm{~N}_{3}$, and $\mathrm{N}_{4}$ tree categories, suggesting predominantly local dispersal and subsequent infection from an initial infected tree taking place at the scale of the interplant spacing ( 3 to $5 \mathrm{~m}$ ) (i.e., the interplant spacing). Beyond this distance, the efficiency of disease spread rapidly decreased. The O-ring analysis also detected an increased density of diseased trees over the same small distances, despite the low level of precision of the GPS device we used. Thus, both analyses are in agreement.

Focus initiation was revealed from the frequency of the $\mathrm{N}$ tree category. These trees were more than 12 to $15 \mathrm{~m}$ distant from any other infected tree and were always more frequently detected than $\mathrm{N}_{2}, \mathrm{~N}_{3}$, and $\mathrm{N}_{4}$ trees, indicating that they do not result from the same dissemination mechanism. The interfoci distance distribution (Fig. 2D) helps with interpretation. In $50 \%$ of cases, the distance was smaller than $10 \mathrm{~m}$ and we assume that this is related to the shortdistance, focus expansion process. However, in $20 \%$ of the cases, the interfoci distance was greater than $15 \mathrm{~m}$, with two cases being greater than $100 \mathrm{~m}$. In these cases, a neighbor-to-neighbor contamination process cannot be responsible for the observations made and we have to assume the possibility of a long-distance dispersal mechanism. Moreover, O-ring analysis indicated that the spatial distribution of the isolated $\mathrm{N}$ trees (a single tree, $\mathrm{S}$ foci category) was not always random but under the influence of either old foci or large foci as far away as 40 to $60 \mathrm{~m}$ (Fig. 2B and C). Because large foci develop over a long period of time compared with small foci, they can be considered to be older than small foci. Therefore, we can assume that old foci were the source of the inoculum that initiated the distant isolated foci.

Short-distance dissemination of CWD can be explained by the dispersal of fungal spores (ascospores and conidia) by splash or by water run-off (Ploetz 2006). It could also result from root contact between infected and healthy coffee trees. Saccas $(1951,1956)$ hypothesized that aerial transport of ascospores produced by fruiting bodies (pycnidia) on the trunks of dying coffee trees was responsible for long-distance dissemination. Aerial transport is not incompatible with the current knowledge about other Fusarium spp. Aerial dispersal has been demonstrated in perennial crops for F. circinatum on pine (Garbelotto et al. 2008) and F. mangiferae on mango (Gamliel-Atinsky et al. 2009) and in annual crops for G. zeae on wheat and maize (Francl et al. 1999; Paul et al. 2004; Schmale et al. 2005) and F. oxysporum f. sp. lycopersicii on tomato (Katan et al. 1997). Despite this, aerial dispersal remains to be demonstrated for CWD on coffee. Other mechanisms may also be responsible for long-distance dissemination of CWD such as human-assisted transport of infected plant material (e.g., via contaminated working tools) or even insect vectors, as is the case of F. sacchari on sugar cane (Ploetz 2006). However, none of these mechanisms have been documented for CWD and their role in dispersal is unknown. During our survey, we saw nothing to suggest their existence: we never observed any alignment of dead trees that could be associated with contaminated tools and we did not detect diseased trees in the nursery where replacement trees were grown.

At the large scale of the entire Kaweri estate, plant age was an important explanatory factor for the variation in CWD incidence observed. Cumulative disease incidence was 10 times greater in old plantings (2001 and 2002) than in younger ones (2003 and 2004) (Fig. 5A to D). To explain this, we propose the following hypothesis. Disease had developed for a longer period of time on old plantings than on young ones ( 7 and 6 years old versus 5 and 6 years old) before regular control measures were implemented in 2008. The time difference may have favored the initiation and development of a greater number of foci in old plantings. On young plantings, fewer foci may have been initiated and they had less time to expand further, resulting in their smaller size. Consequently, it is possible that the control measures were more efficient in reducing disease development in young plantings than in older plantings because disease pressure was reduced and easier to contain. Our survey did not capture information about foci size and number, which could have helped confirm this hypothesis. To achieve confirmation, an aerial survey of the estate may be a more effective protocol than the ground survey we implemented, because it would be easier and faster.

The positive block-environment association detected from the Moran Index and LISA calculation of the $\mathrm{N}$ tree data suggests that a homogeneous dissemination process was responsible for crosscontamination at the scale of a few hundred meters to $1 \mathrm{~km}$ between the blocks within the clusters detected (Figs. 6 and 7). This result supports the hypothesis that there is an aerial dissemination phase in CWD; an ascospore trapping experiment would confirm this, or rule it out. The clusters detected in the case of $\mathrm{N}_{1}, \mathrm{~N}_{2}, \mathrm{~N}_{3}$, and $\mathrm{N}_{4}$ tree categories (Figs. 8 and 9) are more difficult to interpret because it is hard to explain how infection of these trees, possibly resulting from a short-dissemination process, could influence the level of disease in neighboring blocks. In this case, we have to assume that interactions among blocks may result from either (i) the expanding activity of an abnormally high (or low) number of foci or (ii) the fact that environmental conditions experienced at these sites were more (or less) conducive to focus expansion. Greater or lesser efficiency of the control protocol implemented would influence this. The cluster with the greatest frequency of $\mathrm{N}_{1}, \mathrm{~N}_{2}, \mathrm{~N}_{3}$, and $\mathrm{N}_{4}$ trees was located in an area of the estate with an overall low incidence level (Figs. 5 and 9); therefore, it appears that hypothesis 1 can be abandoned. The second possibility may be responsible but cannot be tested with the available data. It requires complementary observations to determine which factors (environment parameters or the control protocol) may have had greatest influence.

On the Kaweri estate, CWD control relies entirely on roguing and delayed replanting, which is the only method currently recommended to reduce the impact of disease (Tshilenge-Djim et al. 1998; Van der Graaff and Pieters 1978). Despite control measures, the disease continued to spread throughout our study period, following a dual dissemination pattern that was a combination of short- and long-distance dispersal, which is frequently observed for plant disease (Marco et al. 2011; Zadoks and van den Bosh 1994). This indicates that control measures did not stop the production and

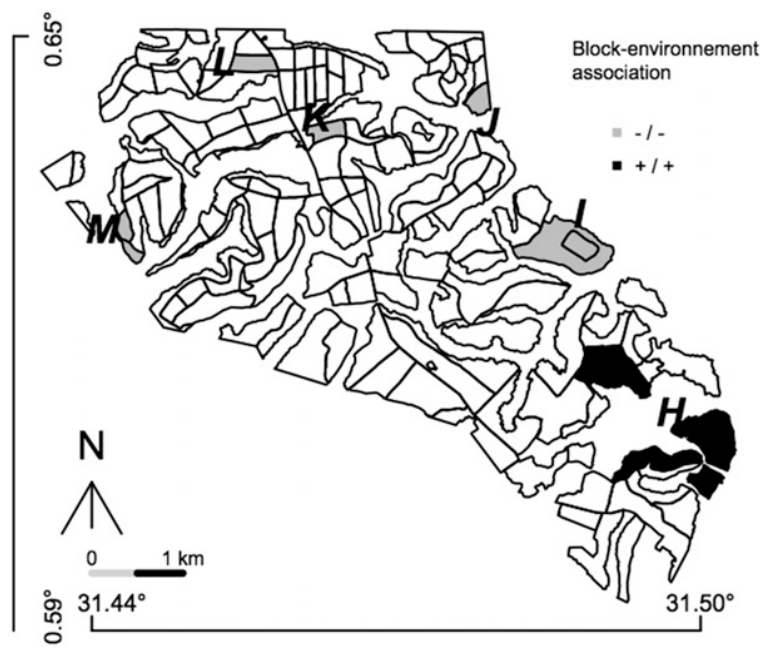

Fig. 9. Map showing the locations of blocks with significant blockenvironment associations at Kaweri estate with respect to clustered infected tree categories (N1, N2, N3, and N4 types). Dark areas (+/+) indicate significant block-environment association with high levels of disease incidence: $\mathrm{H}=$ blocks Luw FO, GA, A4, A5, A6, B1, and B2. Gray areas (-/-) indicate significant block-environment association with low levels of disease incidence: $\mathrm{I}=$ blocks $\mathrm{Kita} 1 \mathrm{~K}$ and $2 \mathrm{~K}, \mathrm{~J}=$ block Non $11 \mathrm{~A}, \mathrm{~K}=$ block Non $4 \mathrm{C}$, $\mathrm{L}=$ blocks Kyam $1 \mathrm{~B}$, and $\mathrm{M}=$ blocks Kyam $5 \mathrm{E}$ and $5 \mathrm{~F}$. 
dispersal of inoculum at Kaweri. This implies that either (i) a diseased tree is infectious before it is removed (for example, in the case of late detection or during the symptomless phase of the disease that cannot be detected using current methods) or (ii) inoculum is able to survive and remain infectious elsewhere (for example, in the soil or on decaying wood remaining after tree removal). In either case, early roguing would reduce the infectious period of a diseased tree. Therefore, the ability of such trees to support focus expansion is reduced and, consequently, expansion velocity of such foci is reduced (Zadoks and van den Bosh 1994). We assume that this explains what we observed at Kaweri at the 1- to $15-\mathrm{m}$ scale. Without roguing, larger and faster foci expansion would have probably been observed. New, isolated foci also continued to occur on the estate throughout our study period. A possible explanation for this observation is that, despite roguing, some inoculum generated on the estate was dispersed over long distances and able to initiate new infection sites. Roguing logically reduced the number of such events but did not prevent their occurrence. It also did not prevent the development of large areas of high incidence (Fig. 7). It is assumed that, without roguing, such areas would probably be more numerous or larger and could have developed sooner. A second possible explanation could be that, independent of the roguing protocol, new foci could have been initiated from an external inoculum source originating outside of the estate. It is also possible that both internal and external sources of inoculum are involved.

Under specific conditions, roguing (combined or not with replanting) is considered to be a valuable control strategy for perennial crop disease management (Chan and Jeger 1994; van den Bosh and de Roos 1996). Although it is highly probable that roguing reduced disease incidence on the estate, the measure also seemed to have some limitations. It was more efficient at reducing the speed of disease progression in young plantings than in older ones (Fig. 5). We suggest that the parameters of the roguing protocol implemented at Kaweri may be responsible for this. For example, the frequency of the detection surveys (monthly) and the efficiency of the rate of detection (unknown) are more effective in reducing disease development in young plantings than in old ones. When regular detection and roguing were initiated in 2008, old plantings already had three to five times higher incidences of CWD than young ones, and disease progression was faster on the old plantings. These initial conditions probably led to different levels of control efficiency, monthly detection being sufficient to maintain the disease incidence at low level on young plantings but not on old ones. This observation suggests the existence of a threshold value, depending at least on the number of infected trees and the frequency of detection, above which roguing and replanting is insufficient to limit or slow down disease progression. Modeling disease dynamics with roguing and replanting would be useful to estimate this threshold value which, currently, can only be derived from a trial-and-error management strategy.

Roguing is costly and difficult to implement rigorously. It requires timely and fast action. In the smallholder context of Uganda, Ethiopia, and Tanzania, the technique is not widely used and, thus, is even less efficient. Our work showed the importance of a longdistance dispersal phase in the spread of CWD. This is probably related to an aerial phase of dispersal which is responsible for the initiation of new foci. It may also play an important role in the focus expansion process but this remains to be demonstrated. The results will underpin new research on control techniques for CWD aimed at the protection of healthy trees from aerial infection. Such measures could provide more efficient disease control.

\section{APPENDIX 1}

O-ring general description and properties. Introduced by Wiegand et al. (1999) and Wiegand and Moloney (2004)), the Oring statistic can be easily presented with reference to the Ripley's $\mathrm{K}$-function, which is more frequently used for spatial point pattern analysis.
By definition, " $K(r)$ is the expected number of points $E(r)$ in a circle of radius $r$ centered at an arbitrary point, divided by the intensity $\lambda$ of the pattern" (Wiegand and Moloney 2004):

$$
\mathrm{E}(\mathrm{r})=\lambda \mathrm{K}(\mathrm{r})
$$

An estimate of $\mathrm{K}(\mathrm{r})$ provides a useful statistic that can be compared with the expected value of a complete spatially random distribution process, generally a Poisson process, commonly used as the null model (Baddeley and Turner 2005). The extent to which $\mathrm{K}(\mathrm{r})$ deviates from the null model indicates aggregated or overdispersed patterns. Deviations from the null model may reflect underlying processes like attraction or repulsion.

The K(r) function is cumulative. All the information related to a circle of radius $\mathrm{r}$ is combined as a summary statistics to describe what is happening to $r$ (Wiegand and Moloney 2004).

An alternative approach to the $\mathrm{K}$ function is the pair correlation function $g(r)$ of the point pattern (Stoyan and Stoyan 1994) where $g$ considers a ring instead of a circle; formally, $g(r)$ was the derivative $\mathrm{K}^{\prime}(\mathrm{r})$ of $\mathrm{K}(\mathrm{r})$, divided by $2 \Pi \mathrm{r}$ :

$$
\mathrm{g}(\mathrm{r})=\mathrm{K}^{\prime}(\mathrm{r}) / 2 \Pi \mathrm{r}
$$

Wiegand et al. (1999) defined the O-ring statistic O(r), analogous to $\mathrm{K}(\mathrm{r})$, as:

$$
\mathrm{O}(\mathrm{r})=\lambda \mathrm{g}(\mathrm{r})
$$

$\mathrm{O}(\mathrm{r})$ is the expected number of points at distance $r$ from an arbitrary point. Being noncumulative, " $\mathrm{O}(\mathrm{r})$ is equivalent to a probability density function, with the interpretation of a neighborhood density, which is more intuitive than a cumulative measure" (Wiegand and Moloney 2004), where $\mathrm{g}(\mathrm{r})>1$ is indicative of an aggregation pattern while $\mathrm{g}(\mathrm{r})<1$ is indicative of overdispersion.

The O-ring statistics can be calculated from a monotype (univariate) point pattern where only one category of point is present. It can also be calculated from a multitype (bivariate) point pattern including two point categories. In this case, the O-ring statistic helps in the detection of possible interactions between categories because O-ring deviation from random density values will indicate attraction (positive deviation) or repulsion (negative deviation) between categories (Jacquemyn et al. 2010; Marcon and Puech 2012; Wiegand and Moloney 2004).

Edge correction. Both $\mathrm{g}(\mathrm{r})$ and $\mathrm{K}(\mathrm{r})$ may be biased by an edge effect, which reduces the number of neighboring points located near the border of the studied area. Several correction methods exist to prevent bias. Ripley (1988) refers to six of them based on various mathematical considerations and on whether the studied area is of a regular or irregular shape. The Statspat package for $\mathrm{R}$ used in this study proposes the four most common of these correction methods as options.

\section{APPENDIX 2}

Moran index (I) general considerations. The Moran's index (I) is a spatial autocorrelation statistic which measures the level of correlation between observations which are close to each other in space (Chessel and Thioulouse 2003). The null hypothesis $(I=0)$ assumes that the variable is independently and identically distributed. Like a correlation coefficient, the index $-1<\mathrm{I}<1$; I $>0$ when observations close in space are positively correlated (positive association) while $\mathrm{I}<0$ denotes a negative association.

The definition of neighborhood is quite important in the statistics estimation because it directly influences the index value. Many definitions of neighborhood exist based on the various criteria available to define what a neighbor is. In this study, the neighborhood of a given block includes all surrounding blocks that are less than the maximum distance between two contiguous blocks on the estate. For such a neighborhood, the I index is maximum and no block is excluded from the analysis. 


\section{ACKNOWLEDGMENTS}

We thank the management and technical staff at the Kaweri Coffee Estate for their cooperation and commitment to conducting this research, R. Copland for proofreading the manuscript, and F. Ribeyre for her comments on the statistical analysis. This study was part of the project "Connecting, enhancing and sustaining environmental services and market values of coffee agroforestry in Central America, East Africa and India" (CAFNET), which was financed by the European Commission Programme on Environment in Developing Countries (EuropeAid/121998/C/G).

\section{LITERATURE CITED}

Anselin, L. 1995. Local indicators of spatial association. Geogr. Anal. 27: 93-115.

Baddeley, A., and Turner, R. 2005. Spatstat: An R package for analyzing spatial point patterns. J. Stat. Software 12:1-42.

Bivand, R. S., Hauke, J., and Kossowski, T. 2013b. Computing the Jacobian in Gaussian spatial autoregressive models: An illustrated comparison of available methods. Geogr. Anal. 45:150-179.

Bivand, R. S., Pebesma, E. J., and Gomez-Rubio, V. 2013a. Applied Spatial Data Analysis with R, 2nd ed. Springer, New York.

Booth, C. 1971. Page 237 in: The Genus Fusarium. Commonwealth Agricultural Bureaux for the Commonwealth Mycological Institute, Kew, London, UK.

Buddie, A. G., Crozier, J., Rutherford, M. A., Flood, J., and Bridge, P. D. 2015. Population development within the coffee wilt pathogen Gibberella xylarioides reflects host-related divergence. Eur. J. Plant Pathol. 142:291-304.

Chan, M.-S., and Jeger, J. 1994. An analytical model of plant virus disease dynamics with roguing and replanting. J. Appl. Ecol. 31:413-427.

Chessel, D., and Thioulouse, J. 2003. Biométrie et génétique évolutive. Analyse de données spatialisées. Online publication. http://pbil.univ-lyon1.fr/ R/pdf/bsa.pdf

Cliff, A. D., and Ord, J. K. 1981. Page 266 in: Spatial Processes, Models and Applications. Pion, London.

Delassus, M. 1954. La trachéomycose du caféier. Bull. Sci. Minist. Colon. Sect. Agron. Trop. 5:345-348.

Francl, L. J., Shaner, G., Bergstrom, G., Gilbert, J., Pedersen, W., Dill-Mackey, R., Sweets, L., Corwin, B., Jin, Y., Gallenberg, D., and Wiersma, J. 1999. Daily inoculum levels of Gibberella zeae on wheat spikes. Plant Dis. 83:662-666.

Gamliel-Atinsky, E., Sztejnberg, A., Maymon, M., Shtienberg, D., and Freeman, S. 2009. Inoculum availability and conidial dispersal patterns of Fusarium mangiferae, the causal agent of mango malformation disease. Phytopathology 99:160-166.

Garbelotto, M., Smith, T., and Schweigkofler, W. 2008. Variation in rates of spore deposition of Fusarium circinatum, the causal agent of pine pitch canker over a 12- month-period at two locations in northern California. Phytopathology 98:137-143.

Girma, A., and Hindorf, H. 2001. Recent investigation on coffee tracheomycosis, Gibberella xylarioides (Fusarium xylariodes), on Arabica coffee in Ethiopia. In: Proc. 19th Int. Sci. Colloq. Coffee (ASIC). ASIC, Trieste, Italy.

Jacquemyn, H., Endels, P., Honnay, O., and Wiegand, T. 2010. Evaluating management interventions in small populations of a perennial herb Primula vulgaris using spatio-temporal analyses of point patterns. J. Appl. Ecol. 47:431-440.

Jacques-Felix, H. 1954. La carbunculariose. Bull. Sci. Minist. Colon. Sect. Agron. Trop. 5:296-344.

Katan, T., Shlevin, E., and Katan, J. 1997. Sporulation of Fusarium oxysporum f. sp. lycopersici on stem surface of tomato plants and aerial dissemination of inoculum. Phytopathology 87:712-719.
Kranz, J., and Mogk, M. 1973. Gibberella xylarioides Heim et Saccas on Arabica coffee in Ethiopia. Phytopathology 78:365-366.

Lejeune, J. B. H. 1958. Rapport au Gouvernement Imperial d'Ethiopie sur la production caféière. Rapport de la FAO 158/3/1881. FAO, Rome.

Madden, L. V., and Hughes, G. 1995. Plant disease incidence: Distributions, heterogeneity, and temporal analysis. Annu. Rev. Phytopathol. 33:529-564.

Marco, D. E., Montemurro, M. A., and Cannas, S. A. 2011. Comparing short and long-distance dispersal: Modelling and field case studies. Ecography 34:671-682.

Marcon, E., and Puech, F. 2012. A typology of distance-based measures of spatial concentration. Online publication. AgroParisTech. https://hal-agroparistech. archives-ouvertes.fr/halshs-00679993v3/document

Meifren, M. 1961. Contribution aux recherches sur la trachéomycose du caféier en Côte d'Ivoire. Cafe Cacao Thé V:28-37.

Moran, P. A. P. 1948. The interpretation of statistical maps. J. Roy. Stat. Soc. B 10:243-251.

Musoli, C. P., Pinard, F., Charrier, A., Kangire, A., Ten Hoopen, G. M., Kabole, C., Ogwang, J., Bieysse, D., and Cilas, C. 2008. Spatial and temporal analysis of coffee wilt disease caused by Fusarium xylarioides in Coffea canephora. Eur. J. Plant Pathol. 122:451-460.

Ohser, J. 1983. On estimators for the reduced second moment measure of point processes. Math. Operationsforschung Stat. Ser. Stat. 14:63-71.

Paul, P. A., El-Allaf, S. M., Lipps, P. E., and Madden, L. V. 2004. Rain splash dispersal of Gibberella zeae within wheat canopies in Ohio. Phytopathology 94:1342-1349.

Ploetz, R. C. 2006. Fusarium-induced diseases of tropical, perennial crops. Phytopathology 96:648-652.

Renaud, D. 1958. La trachéomycose des caféiers en Afrique. Marchés Tropicaux Février 58:498-500.

Ripley, B. D. 1988. Statistical Inference for Spatial Processes. Cambridge University Press, Cambridge, UK.

Rutherford, M. A. 2006. Current knowledge of coffee wilt disease, a major constraint to coffee production in Africa. Phytopathology 96:663-666.

Saccas, A. M. 1951. La tracheomycose (carbunculariose) des Coffea excelsa, neo-arnoldiana et Robusta en Oubangui-Chari. Agron Trop. VI:453-506.

Saccas, A. M. 1956. Recherches expérimentales sur la trachéomycose des caféiers en Oubangui-Chari. Agron. Trop. XI:8-38.

Schmale, D. G., Shah, D. A., and Bergstrom, G. C. 2005. Spatial patterns of viable spore deposition of Gibberella zeae in wheat fields. Phytopathology 95:472-479.

Stoyan, D., and Stoyan, H. 1994. Fractals, Random Shapes and Point Fields: Methods of Geometrical Statistics. Wiley, Chichester, UK.

Tshilenge-Djim, P., Kalonji-Mbuyi, A., Onyembe, P. M. L. A., Mukuna, J. M., Dibwe, D., and Oripal, M. 1998. Caractéristique et évolution spatio-temporelle de la trachéomycose fusarienne du caféier Robusta en République Démocratique du Congo. Rev. Cong. Sci. Nucl. 14:132-140.

van den Bosh, F., and de Roos, A. 1996. The dynamics of infectious diseases in orchards with roguing and replanting as control strategy. J. Math. Biol. 35:129-157.

Van der Graaff, N. A., and Pieters, R. 1978. Resistance levels in Coffea arabica to Gibberella xylarioides and distribution patterns of the disease. Neth. J. Plant Pathol. 84:117-120.

Wiegand, T., and Moloney, K. A. 2004. Rings, circles, and null-models for point pattern analysis in ecology. Oikos 104:209-229.

Wiegand, T., Moloney, K. A., Naves, J., and Knauer, F. 1999. Finding the missing link between landscape structure and population dynamics: A spatially explicit perspective. Am. Nat. 154:605-627.

Zadoks, J. C., and van den Bosh, F. 1994. On the spread of plant disease: a theory on foci. Annu. Rev. Phytopathol. 32:503-521. 